\title{
Expressivism at the beginning and end of life
}

\author{
Philip Reed
}

Philosophy, Canisius College, Buffalo, NY 14209, USA

Correspondence to Dr Philip Reed, Philosophy, Canisius College, Buffalo, NY 14208, USA: reedp@canisius.edu

Received 1 October 2019 Revised 13 December 2019 Accepted 17 February 2020 Published Online First 1 July 2020

\section{Linked}

- http://dx.doi.org/10.1136/ medethics-2020-106372

- http://dx.doi.org/10.1136/ medethics-2020-106375

- http://dx.doi.org/10.1136/ medethics-2020-106376

- http://dx.doi.org/10.1136/ medethics-2020-106521

- http://dx.doi.org/10.1136/ medethics-2020-106533

\section{Check for updates}

(C) Author(s) (or their employer(s)) 2020. No commercial re-use. See rights and permissions. Published by BMJ.

To cite: Reed P. J Med Ethics 2020;46:538-544.

\section{ABSTRACT}

Some disability rights advocates criticise prenatal testing and selective abortion on the grounds that these practices express negative attitudes towards existing persons with disabilities. Disability rights advocates also commonly criticise and oppose physician-assisted suicide (PAS) and euthanasia on the same grounds. Despite the structural and motivational similarity of these two kinds of arguments, there is no literature comparing and contrasting their relative merits and the merits of responses to them with respect to each of these specific medical practices. This paper undertakes such a comparison. My thesis is that a number of potentially significant weaknesses of the expressivist argument against reproductive technologies are avoided when the argument is used against PAS. In particular, I try to show that three common criticisms of the expressivist argument applied to reproductive technologies, whatever merit they have, have even less merit when they are used to reply to the expressivist argument applied to PAS. This is important because the expressivist argument applied to the end of life scenario does not get as much attention as the argument applied to the beginning of life scenario, and yet it has a relatively stronger position.

Some disability rights advocates criticise prenatal testing and selective abortion when these are used to prevent disabled individuals from being born. These practices, it is said, express negative attitudes towards existing persons with disabilities. This is known as the expressivist argument (or expressivist objection), which has spawned a substantial literature in bioethics.

Disability rights advocates also commonly criticise and oppose physician-assisted suicide (PAS) and euthanasia. One reason they do this is that such practices, they say, express negative attitudes towards existing persons with disabilities.

Despite the structural and motivational similarity of these two kinds of arguments, there is no literature comparing and contrasting their relative merits and the merits of responses to them with respect to each of these specific medical practices. This paper undertakes such a comparison.

My thesis is that a number of potentially significant weaknesses of the expressivist argument against reproductive technologies are avoided when the argument is used against PAS. I do not especially wish to evaluate the merits of the expressivist argument on their own with respect to either prenatal screening or PAS. Instead, my central point is the more limited and relative one that this argument

${ }^{\mathrm{i}} \mathrm{A}$ good starting point is. ${ }^{25}$ is much stronger when it is used to criticise PAS compared with when it attacks prenatal testing. In particular, I try to show that three common criticisms of the expressivist argument applied to reproductive technologies, whatever merit they have, have even less merit when they are used to reply to the expressivist argument applied to PAS. This is important because the expressivist argument applied to the end of life scenario does not get as much attention as the argument applied to the beginning of life scenario, and yet it has a relatively stronger position.

The first section outlines the expressivist argument at both the beginning and end of life. The second section, the heart of the paper, shows how the end of life context better deals with several objections. The final section briefly draws out some implications of my thesis.

\section{THE EXPRESSIVIST ARGUMENT}

In the 1970s and 1980s various biotechnologies began to improve significantly the ability to diagnose genetic defects or fetal abnormalities very early in pregnancy and sometimes, for example, in the case of in vitro fertilisation and preimplantation genetic diagnosis, even before pregnancy begins. Around the same time, bioethicists and physicians began defending the use of these biotechnologies for the purpose of selective termination against fetuses or embryos that were likely to have disabling traits on the grounds that preventing an individual with a disability from being born would promote human well-being. As a response, disability rights advocates commonly objected to these practices and their defenses as discriminatory. ${ }^{12}$ These critics did not object to abortion and screening techniques as such, but only when they were used specifically to target disabilities. In other words, disability rights advocates did not have any of the prolife concerns that are sometimes made against both abortion and embryo destructive reproductive technologies.

How exactly to characterise the expressivist argument is a matter of some dispute, but probably the strongest way to put the objection is that the use of reproductive biotechnologies to prevent the existence of disabled individuals often expresses a negative belief about or attitude towards existing disabled individuals. ${ }^{\text {ii }}$ The most commonly recognised negative attitude is disrespect. Prenatal screening disrespects existing disabled persons, the expressivist argument holds, because it reduces the

${ }^{i i}$ For a comprehensive outline of the different forms that the expressivist argument can take. ${ }^{21}$ 
value of such persons to their disabling trait and implies the negative belief that the lives of disabled persons are not worth living.

As mentioned above, we see a very similar argument used against PAS and euthanasia.i.i For example, Diane Coleman observes that 'For individuals who internalise the social oppression that declares severe disability to be undignified, the legalisation of assisted suicide may convey the message that suicide is the best way to reclaim their dignity' (Coleman, p228). ${ }^{3}$ Felicia Ackerman writes that 'allowing assisted suicide for the terminally ill...but not for people facing other severe and irremediable misfortunes, involves a systematic devaluation of the lives of the terminally ill' (Ackerman, p154). ${ }^{4}$ And John Keown argues that 'the very fact of decriminalisation [of laws against euthanasia] could easily signal to vulnerable groups, directly or indirectly, not only that they may seek an earlier death, but that they should' (Keown, p96). ${ }^{5}$ iv In other words, when we allow PAS for individuals who are terminally ill or facing some severe disease or disability, we send a message of disrespect to all individuals who face such adversities in that we imply that they are inferior or their lives are not worth living (or at least less worth living than they otherwise would be) precisely insofar as they are diseased or disabled.

It is interesting that when this objection is made against PAS, it is not identified as an 'expressivist' argument. ${ }^{\mathrm{V}}$ It seems obvious that the objection at the end of life has the same structural and motivational similarity as what is identified as the expressivist argument at the beginning of life. Why bioethicists do not point out this similarity is unclear to me. It cannot be merely that, for example in the characterisations of the objection above, no mention of the verb 'express' is used. Surely the idea of conveying a message or of indirect signalling is precisely what is identified as problematic in the beginning of life scenario. Part of the explanation for why this objection has not been labelled as expressivist may be that there is a cluster of different objections against PAS based on disability rights, and the expressivist objection is only one of them. The expressivist objection tends not to be the most prominent or common one made against PAS, perhaps because it is not thought to be the most important. But there is also a cluster of different objections that disability rights advocates have made against prenatal testing, and this has not prevented the identification of one particular objection as expressivist.

Another possible explanation for why the expressivist argument at the end of life is not so labelled is that the target of the questionable practice might be considered to be less precise than at the beginning of life. When reproductive biotechnologies are used to prevent the births of individuals, they tend to particularly target disability. However, it might be said, laws permitting PAS and euthanasia do not particularly target disability. Instead, they allow for the option of medically assisted death under a range of different considerations. While this might be part of the (sociological) explanation for why the expressivist argument is not identified as such in the context of medically assisted death, it is not a good reason for denying that the expressivist argument

\footnotetext{
iii ‘Euthanasia' refers to voluntary active euthanasia. I sometimes use the phrase 'medically assisted death' to refer to both euthanasia and PAS. For the most part, I do not sharply distinguish between PAS and euthanasia for the purposes of this paper.

${ }^{\text {iv }}$ For other versions of the expressivist argument (though not under that name) at the end of life. ${ }^{2426-28}$

${ }^{\mathrm{v}}$ To my knowledge, the only exception is Scoccia, ${ }^{29}$ and he does not say anything about this objection as it compares to reproductive biotechnologies.
}

actually applies in that context. All current laws permitting medically assisted death limit eligibility to individuals suffering from either a terminal or incurable illness. The natures of and relationship between illness and disability are obviously complex and beyond the scope of this paper. However, most accounts of disability are broad enough such that they would include people suffering from terminal and incurable illnesses as disabled. This is because terminal and incurable illnesses are associated with a loss or limitation of a broad range of capabilities. While terminal cancer, say, is not usually thought of as a (paradigm instance of) disability, it nevertheless normally leads to substantial restrictions on significant physical and social activities. Therefore, most persons who qualify to use medically assisted death will have a disability to some extent according to most theories of disability. ${ }^{\text {vi }}$ In other words, the class of ill people who quality for euthanasia or assisted suicide are a subsection of the disabled insofar as they include individuals who experience capacity limitations or significant prevention of ability to exercise normal activities. In this way, medically assisted death laws do at least implicitly target disabled individuals.

Moreover, the reasons that people adopt euthanasia or assisted suicide deal precisely with the loss or limitation of a broad range of capabilities. The relevant kind of suffering that worries those with incurable and terminal illnesses and motivates them to adopt medically assisted death is not usually physical suffering (as is popularly thought) but rather psychological and existential suffering. ${ }^{6-8}$ For example, the most common reasons that terminally ill individuals in Oregon choose PAS are that they do not wish to lose autonomy, 'dignity', the ability to engage in normal activities, or control of their bodily functions. ${ }^{9}$ In other words, the loss of different abilities, they judge, makes their life not worth living. Medically assisted death offers the terminally or incurably ill person either relief from his loss of normal human activities such as moving about, continence, social engagement, and so on, or the promise that he can die before he loses them. Disability rights groups correctly point out that these are precisely disability-related concerns. Hence, it is not a coincidence that every national disability rights organisation that has taken a position on the issue of medically assisted death is opposed. ${ }^{10}$ vii There is good reason for disability rights advocates to be concerned about the message about disabilities that is expressed by the legalisation of PAS and euthanasia. ${ }^{\text {viii }}$

Ultimately, it does not matter whether the expressivist argument at the end of life gets labelled as 'expressivist'. But insisting on this point, regardless of whether anything else I say in this paper is convincing, makes two contributions to the end of life debate. First, it clarifies one kind of disability rights argument against PAS. The

\footnotetext{
${ }^{\text {vi }}$ For some support for this claim. ${ }^{31730}$

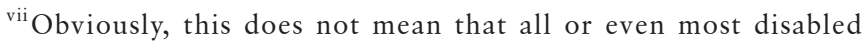
individuals necessarily oppose PAS.

viii If one still finds the connection between medically assisted death laws and disability too loose, I suggest it is no looser than the connection between prenatal testing and disability. Prenatal testing, like PAS, targets only a subsection of the disabled, but that does not usually prevent us from saying that its target (at least in part) is the disabled tout court. Moreover, prenatal testing does not limit itself merely to paradigm cases of disability, but a range of different diseases and disorders (eg, cystic fibrosis) that, depending on the account of disability that is offered, may or may not count as a disability. There do not seem to be any worries about the vagueness of disability or its relationship to disease that are launched as an objection to whether we should consider the implications embryo screening and fetal diagnosis has for the disabled and our attitudes towards life with disabilities.
} 
expressivist argument, which objects to PAS on the grounds that it will affect disabled individuals who do not even choose assisted suicide, is not the same, for example, as the argument that disabled people will be pressured into choosing assisted suicide against their will. But I will suggest at the end of the paper that these arguments are not independent. Second, identifying the expressivist argument at the end of life as expressivist enables a comparison to a similar argument at the beginning of life. This can be fruitful, I contend, because the literature on the objection with respect to reproductive technologies is considerably advanced. I turn next to the comparison between the two contexts.

\section{OBJECTIONS TO EXPRESSIVISM}

The objections I consider against the expressivist argument are not exhaustive. Instead, my aim is merely to examine some of the most prominent objections against expressivism at the beginning of life and see how they fare with respect to expressivism at the end of life. The reader, moreover, should be reminded that my principal goal is not to evaluate these objections on their own merits.

The first objection is that the negative belief or attitude that is allegedly expressed by reproductive biotechnologies when used to select against disability is not actually expressed. This is because, first of all, the negative belief might not be in fact present in the individuals who use these technologies and/or the negative belief or attitude might not play a role in the decision to use them. Allen Buchanan insists that a woman who aborts a fetus that is likely to have Down syndrome, for example, need not be committed to saying that life with Down syndrome is not worth living. Instead, she might just be saying that she is not prepared emotionally or financially to raise a child with Down syndrome. ${ }^{11}$ ix Second, the negative belief might not be expressed because of the difficulty of identifying the message of social or medical practices. Jamie Lindemann Nelson observes that even if individual choices might not reveal a disrespectful intention, social practices on the whole might. Yet, she insists, reproductive technologies are social practices whose meanings are vague and ambiguous, so we cannot be sure that any negative message is actually expressed. ${ }^{12 \times}$

How does this objection fare in the end of life context? Not well. The legalisation and use of PAS or euthanasia expresses a much more determinate message than that of reproductive biotechnologies. Fundamentally, assisted death is almost always chosen while holding the belief that life is not worth living (or would not be worth living) under the condition of one's illness and associated loss of capabilities. This is not merely a background belief, but almost invariably plays a role in the decision to die. It is far more unlikely for an individual to adopt a medically assisted death because, for example, she is not prepared financially to undergo a terminal or incurable illness. Instead, she is very likely to think that the quality of her life will be so poor that she would be better off dead, which is exactly the expressivist concern. If the grounds for her believing that her life is not worth living involve her loss of capabilities, as we have seen that it almost always does for patients who choose to die, then the negative attitude towards life with a disability plays a

\footnotetext{
${ }^{\text {ix }}$ While this message would avoid expressing the message that the lives of those with Down syndrome are not worth living, it does seem to express the message that the lives of those with Down syndrome are a severe burden, which might also be disrespectful. ${ }^{x}$ For some version of this objection against expressivism at the beginning of life. ${ }^{13173132}$
}

role in her choice and so is more likely to express a message of disrespect.

More important, in my view, than the mental states of the individuals who might use some medical practice is the meaning of the social or medical practice itself (expressed, for example, by its legalisation). What kind of message does the legalisation of PAS give? Here, too, the meaning is much more determinate than in the case of legalising reproductive biotechnologies. PAS laws express that individuals who find their terminal or incurable illness unbearable are free to end their lives. The practice of medically assisted death, in other words, says that individuals who wish to die on their own terms can do so, but only if they are among a subsection of the disabled population. Why can't PAS laws merely express the message that society should not interfere with a person who wishes to end his life? They could express this if the right to die were extended to everyone regardless of illness or disability. The fact that the actual laws in place extend eligibility for medically assisted death only to those with some kind of disability suggests that having this kind of disability is often incompatible with a desirable quality of life. In other words, the actual laws that we have that narrow eligibility for assisted death make the meaning of these laws much more specific. If PAS or euthanasia were legal exclusively for the ugly or the unemployed, the message would be that a life of being ugly or unemployed is very often not worth living.

The legalisation and social accessibility of abortion and genetic technologies have a much greater range of possible meanings. Perhaps extending these options to people is about giving them greater reproductive control, for example. A woman might choose to undergo an amniocentesis not for the purpose of selective abortion but for making preparations for a disability diagnosis or, in some cases, for therapeutic interventions during pregnancy. Or consider preimplantation genetic diagnosis; this is used to discard embryos that are likely to have disabilities, and to offer greater genetic control beyond issues of health and disease (such as choosing a child's eye colour). All of these motivations might be judged as morally significant and expressive of the meaning of the relevant practices when society chooses to make them socially available. But the social availability of PAS and euthanasia do not have the same range of possible meanings.

The second objection against expressivism is that the rights to autonomy trump any negative attitudes that might be expressed. One might concede that disrespect is expressed by the use of prenatal screening and selective abortion, but that is not a reason, according to this objection, to deny people the use of this practice if we have good reasons to extend to them this use. And in the case of reproductive technologies, we do have good reasons, namely to give individuals the right to control the circumstances of their own reproduction. Steven Edwards makes the following analogy: 'one may choose to have an abortion in the knowledge that this will offend prolife groups, but it does not follow that the offence caused to these groups outweighs one's right to make such a choice' (Edwards, p419). ${ }^{13}$ xi

If we grant, for the sake of argument, that there is a so-called right to die, it might seem as if a similar point against expressivism can be made in the end of life context: even if PAS or euthanasia disrespects the lives of the disabled, these negative attitudes do not trump legitimate autonomy rights. The reason this line of thinking is less persuasive, however, is that there is a significant

${ }^{x i}$ For some version of this objection against expressivism at the beginning of life. ${ }^{173133}$ 
difference between exercising a right to die and exercising a right to reproductive technologies, which is that the former does not require medical assistance in the same way that the latter does. One cannot use prenatal screening on one's own. One cannot even reliably perform an abortion on one's own. But one can normally and reliably end one's life on one's own. This is all the more true now that suicide has been widely decriminalised. Laws permitting assisted suicide and euthanasia involve physicians (and other healthcare practitioners) in something that individuals commonly can, with not too much difficulty, achieve legally and without physician involvement. The same cannot be said with respect to in vitro fertilisation, say, or preimplantation genetic diagnosis. The idea here is not that the extent to which one relies on others determines the 'autonomy' of the decision. The idea is rather that the relevant autonomy right in the two different cases is exercised in different ways: the right to reproductive control is exercised only with the cooperation of the medical profession and the right to die can be exercised independently of third party involvement.

It might be objected that the right to die cannot be exercised safely and painlessly without medical assistance, perhaps like abortion. While there is something to this objection to a point, it nevertheless seems the case that there is still a significant difference in degree. One is much more likely to kill oneself successfully and safely on one's own than one is to carry out an abortion successfully and safely on one's own. Reproductive biotechnologies other than abortion, meanwhile, are not at all possible to carry out on one's own.

It might also be objected that there are cases where disabled people are physically unable to end their own lives due to their disability and so can only exercise their right to die with some kind of assistance. I have three responses to this objection. First, the instances in which disabled people are unable to perform a fatal act because of their disability are not very common. For instance, Carol Gill remarks that "persons with disabilities, like nondisabled persons, are generally capable of carrying out suicide if they are committed to doing so. Persons with even extensive functional limitation are more competent than most people think they are" (Gill, p538). ${ }^{14}$ Second, some jurisdictions such as Switzerland and certain US states, have only extended the right to die to persons who can perform the fatal act on their own, and they have done this presumably because they think that there are good reasons for insisting on this requirement. In these jurisdictions, the right to die does not encompass a right to euthanasia. Now, maybe these jurisdictions have it wrong; maybe they should also extend to disabled persons the right to euthanasia, as other jurisdictions have done. But even if this is true, my third response to this objection is that it still would not challenge my central point, which is that the right to die does not require medical assistance in the way that the right to reproductive autonomy does. If a person is physically unable to self-administer a fatal act, there is no special reason that physicians should do this for them. Physicians are not traditionally trained to end people's lives, which is one reason why they generally refuse to participate in executions. Successfully killing someone, even doing so painlessly, does not take tremendous expertise. If a disabled person needs assistance to end his life, it would be easy for the assistance to come from non-physicians, such as lawyers ${ }^{15}$ or even philosophers; ${ }^{16 \text { xii }}$ the same cannot be said for individuals who

\footnotetext{
xii For more on this point. ${ }^{34}$ Notice that my argument here does not require any strong claims about the purpose of medicine (the so-called internal morality of medicine) or the proper role of physicians. All I'm committed to is the claim that there is no special reason that assistance in death has to be medical.
}

need assistance to exercise an autonomy right over their reproductive choices.

My analysis of this second objection against expressivism at the end of life does not mean, of course, that the objection necessarily fails. The fact that offence or disrespect is expressed by legalising PAS does not entail that we should not legalise PAS. There might be good reasons that justify legalising PAS even in the face of offence and disrespect. Perhaps, the ability to exercise the right to die successfully and painlessly from a friendly doctor should trump any negative attitudes that are expressed. But this is a lot less obvious than the idea that autonomy rights should trump the expression of such attitudes. ${ }^{\text {xiii }}$

The third and final objection to expressivism at the beginning of life is that it's a mistake to think that the use or availability of reproductive biotechnologies expresses a negative attitude towards existing disabled people because the purpose of such practices is to prevent disabled persons from existing in the first place, not to say anything about the lives of such persons who already exist. As Tom Shakespeare, for example, writes: 'Any disabled person has already been born. Prior to being born, the disabled person does not exist in any meaningful sense. During the mother's pregnancy, a cluster of developing cells existed, but not a person with identity, experiences and feelings. The response 'I would not have been born' has an emotional resonance, but cannot be understood in strictly rational terms, because before anyone is born, there is no 'I' not to be born.' (Shakespeare, p89). ${ }^{17}$

In order to make this objection make sense, we have to assume that the embryo and fetus are not persons. The general point is that it is mistaken to find a negative attitude expressed by prenatal testing because prenatal testing does not target anyone who already exists. Imagine if a guardian angel warns you that if you cross the street you will be struck by a car and be paralysed; supposing you decide to refrain from crossing the street, you appropriately prevent a disability but do not thereby express any negative attitudes to people who already have disabilities. ${ }^{18}$ In short, this objection insists that preventing the existence of disabled people who do not yet exist is very different from saying of any already-existing disabled person that her life is not worth living. .iv $^{\text {xiv }}$

As you can probably see already, this objection-which is perhaps the most popular objection against expressivism at the beginning of life-is simply irrelevant in the end of life context. The whole point of the objection is that prenatal testing and abortion are preventative measures-they do not act on any already-existing disabled persons. In this way, they do not make judgments about such persons. However, the medical availability of assisted suicide is not similarly preventative. On the contrary, it acts directly on already-existing disabled individuals. Individuals who are euthanised or who take their own life with a physician's help exist in every meaningful sense. In short, PAS laws target disabled persons themselves compared with prenatal testing or selective abortion, which targets only potential persons.

It's not the case that any suicide whatsoever sends the message that a life with disabilities is a life not worth living. This is because individuals who die by suicide choose to do so for a variety of reasons including revenge, political protest, or unrequited love. None of these cases are cases of disabled people adopting suicide, so no message about disabilities could be expressed. More importantly, laws that allow a certain class of people to legally die by suicide imply, of this class, that their reasons for wanting to die are

\footnotetext{
xiii I return to this second objection against expressivism in the conclusion.

${ }^{x i v}$ For some version of this objection against expressivism at the beginning of life. ${ }^{111319202223}$
} 
perfectly acceptable. As I argued in the previous section, the laws that we in fact have identify this class to be disabled people.

In the context of prenatal testing, this third objection against expressivism is sometimes made by relying on an analogy to disease or illness: just as a commitment to preventing illness does not express negative attitudes to people who are sick, so too we should not think that aiming to prevent disabilities expresses negative attitudes to disabled people. ${ }^{11} 1920$ In reply, a number of philosophers and bioethicists insist that the analogy is misleading because illness (at least short-term illnesses such as the influenza, say) is not a significant part of a person's identity in the way disability can be. These writers insist that disability is comparable to other identity traits such as race, sex or sexual orientation. ${ }^{13} 2122$ Steven Edwards, for instance, remarks that 'whatever force the expressivist objection has appears to rely on the identity claim', which is the claim that disability is 'identity constituting' for at least some people ${ }^{13}$ (Edwards, p419). ${ }^{\mathrm{xv}}$

This point, however, obscures the expressivist argument in two ways. First, it seems to entail the mere difference view of disability: in so far as disability is like race, sex, or sexual orientation, it is a trait that doesn't include any inherent (ie, independent of social or institutional practices and attitudes) limitations, disadvantages, or harms. ${ }^{\text {xvi }}$ Even if the mere difference view of disability were philosophically convincing, the problem with invoking it in this context is that it does not explain why it might be considered legitimate to prevent disability at all. If we were using prenatal screening to prevent the existence of women or gay people, it would be difficult to avoid the conclusion that the motivation (at least in large part) stems from a belief that women or gay people are inferior or undesirable. ${ }^{\text {xvi }}$ It is mistaken, however, to insist that the practice of prenatal testing for disability necessarily stems from a similar belief about disabled people. It makes sense, in other words, to try to block the emergence of disabilities insofar as these are genuine disadvantages (and they would be genuine disadvantages, in my view, even if we eliminated prejudice against disabled persons as well as societal or institutional barriers to their full inclusion).

When, in the context of this debate, one observes that disability can be (at least partially) identity-constituting, one is (at least partially) trying to explain why someone who is disabled

\footnotetext{
${ }^{\mathrm{xv}}$ Asch, however, does not accept that one needs to adopt the identity claim in order to make the expressivist argument. ${ }^{2}$

${ }^{x v i}$ For this view. ${ }^{35}$ Other disability theorists who have adopted the social model of disability have said that having a disability is really just about being differently abled. For criticism. ${ }^{36}$

${ }^{x v i i}$ An anonymous referee contends that most people are unlikely to try to prevent the existence of women or gay people as a class; instead they might reasonably wish to avoid raising a girl or a gay child because they are individually unprepared to do so in the way that others might reasonably wish to avoid raising a disabled child because they are individually unprepared to do so. However, I deny that these cases are analogous in the way the referee proposes. Being female, for example, does not include any inherent limitations or disadvantages. Instead, all of the relevant disadvantages that women experience are socially constructed and imposed. Good people who are concerned about these disadvantages work to change them in society. If they are prepared to raise children at all, they do not try to avoid raising certain kinds of children who face contingent discrimination (and if they did, it would be nearly impossible to disentangle this desire from the relevant social prejudice). On the other hand, what I am suggesting here is that even if we fixed all social structures that impose limitations on disabled people, they would still be disadvantaged, which makes their wish to avoid raising a disabled child more reasonable than those who wish to avoid raising a girl. ${ }^{36}$
}

Table 1 Methods for Reducing the Number of People with a Disadvantageous Condition

Existential methods for reducing the number of persons with disadvantageous condition C

(1) Preventing the existence of such persons. Contraception; abortion

(2) Ending the existence of such persons. Voluntary or involuntary killing or letting die

Non-existential methods for reducing the number of persons with disadvantageous condition C

(3) Preventing the emergence of condition C. Social/biomedical interventions that prevent C

(4) Reversing the emergence of condition C. Social/biomedical interventions that reverse $\mathrm{C}$

would be offended or troubled by the negative attitude being expressed. But the second reason that a focus on the identity issue is unhelpful, I believe, is that this attempt is misguided-it identifies the wrong reason that people are or might be offended by prenatal screening. The reason that one is or might be offended by prenatal screening for disability is not that disability can go to the core of one's identity (even though it can). Instead, the disrespect stems from the way in which the goal of reducing the number of individuals who live with a disability is being carried out. The range of ways in which we might reduce the number of persons with a disadvantageous or limiting condition is represented in table 1 above. Testing for disability is an 'existential method', to coin a term, for reducing the number of disabled persons: it reduces the instances of disability by reducing the number of disabled persons. More formally, an existential method for reducing the incidence of disadvantageous condition $\mathrm{C}$ engages in reducing the existence of individuals with $\mathrm{C}$ who, without engaging in this method, would otherwise exist. There are two ways to go about pursuing this method. We can (1) Prevent the existence of individuals with $\mathrm{C}$ before they exist by using gamete selection, delayed conception (according to some thought experiments, at least), contraception, embryo analysis, genetic modification, or abortion. (2) Or we can terminate the existence of individuals with $\mathrm{C}$ after they exist by killing them (such as by euthanasia) or letting them die (such as by prioritising scarce life-saving resources for the non-disabled).

The appropriate analogy to advance the expressivism debate is not identity traits like race and sex but other disadvantageous conditions like illness, poverty, illiteracy, and addiction. This is the appropriate analogous class even though these conditions are not identity-constituting in the way that disability can be because this class identifies genuine disadvantages or limitations-we can understand the motivation to reduce the number of individuals who have such conditions. And there are a variety of non-controversial ways of doing this. I call these 'non-existential methods' because they do not interfere with the existence of individuals with condition C. ${ }^{\text {xviii }}$ We might, for example, (3) Prevent the emergence of adult illiteracy by improving grade school education. (4) Or we might reverse the emergence of adult illiteracy by expanding literacy education programmes for adults. Similarly, we might, for example, (3) Prevent the emergence of a disability by refusing to cross the street when our guardian angel warns us that crossing the street will cause a

\footnotetext{
${ }^{x v i i i}$ I don't mean to imply that all non-existential methods are acceptable or non-controversial. We might reduce the number of people with addictions, for example, by institutionalising them against their will.
} 
disability. (4) Or we might reverse the emergence of a disability by carrying out a surgery to 'correct' some disability. Other non-existential methods for preventing disability include, for example, a pregnant woman's avoiding drugs and taking proper dietary supplements for the health of the developing fetus or administering vaccines against polio. The point is that the nonexistential methods do not invoke expressivist worries: we do not think a robust social programme to prevent or reduce illiteracy, for example, expresses a negative attitude against illiterate individuals. And even though some disabled individuals would prefer not to have their disability reversed (because it is identityconstituting for them), they do not generally object to offering this possibility to others. Writers who make the expressivist argument against prenatal testing almost never say that nonexistential methods are similarly disrespectful.

However, the existential methods are a different story, for these seem, at least, in danger of expressing negative attitudes against persons who have the relevant disadvantageous condition. Existential methods combat a disadvantageous condition by thwarting, in some way, the existence of persons who experience it. Even though it is uncontroversial to propose programmes to end adult illiteracy, for example, it would be another matter entirely if we (2) offered PAS to illiterate individuals (or to individuals suffering from poverty, chronic illness, or alcoholism) or threw them into a gas chamber. If we did do this, we would clearly be in danger of expressing a belief that a life as an illiterate adult is not worth living (or some other expression of disrespect for such individuals). In other words, ending the existence of someone with a disadvantageous condition expresses a different kind of message from that of the non-existential methods. How we go about reducing the number of individuals with a disadvantageous condition matters a great deal.

Now, I think that whether (1) is an appropriate method for reducing the number of individuals with a disadvantageous condition is an important question. Those who have opposed the expressivist argument at the beginning of life have, in my view, been too quick to assume that there is nothing wrong with it. In fact, opponents of expressivism at the beginning of life who like to emphasise the appropriateness of preventing illness or disease seem to ignore the distinction between (1) and (2) altogether. They ignore this distinction because, just when they show awareness of the importance of how we go about reducing the number of persons with a disabling condition, they give a detailed explanation about how they are assuming that fetuses are not persons. ${ }^{11} 17192023$ In other words, they defend embryo selection and selective abortion on the grounds that it's not an instance of (2). Yet that hardly shows that selective abortion is just as defensible as the non-existential methods of preventing a disadvantageous condition or that it does not express a disrespectful message to people with disabilities. ${ }^{\text {xix }}$ Would a social programme that promotes contraception or abortion among poor people, illiterate people, or people with addictions (supposing that these are likely to be handed down to

\footnotetext{
${ }^{x i x}$ Given the distinction I've drawn between existential and nonexistential methods, it seems to me that it is perfectly reasonable to oppose (1) (as well as (2) of course) but still support (3) and (4). Again, opponents of expressivism sometimes do not seem to realise this. Buchanan, for example, says that if the expressivist argument is sound it would 'rule out a wide range of traditional, 'low-tech' interventions to avoid or remedy disabilities' such as treating babies' eyes at birth to prevent blindness (Buchanan, p23 ${ }^{11}$. Edwards comments that the 'expressivist objection seems to have the implication that it is wrong both first, to seek to prevent any form of disability, and second, to cure or 'put right' any existing disability' (Edwards, p419). ${ }^{13}$
}

offspring) express a negative judgement about such people? It is not obvious that it would not. ${ }^{\mathrm{xx}}$ Preventing the existence of a disadvantaged person on the sole grounds of that disadvantage is much more likely to give the message that life with that disadvantage is not worth living than preventing the emergence of a disadvantage which in no way interferes with a person's existence.

My central point in this paper, however, is not to argue about the appropriateness and meaning of (1), but merely to see that whatever one thinks about this method, it is clear that method (2) raises serious problems. As Buchanan notes, 'one need not and should not wish to reduce the number of people with disabilities by taking the life of any person who is disabled' (Buchanan, pp32-3). ${ }^{11}$ And this means that expressivism at the end of life is a much greater concern than at the beginning. Of course, the fact that in PAS and euthanasia we take the life of a person with that person's consent is morally relevant and very important, but it doesn't obviously affect what kind of belief or attitude is expressed, which is at issue here. The expressivist argument is an argument about how a specific practice affects the disabled community in general rather than the target of the practice itself (fetus, terminally ill patient), so we can set to one side the issue that this is a voluntary killing.

\section{CONCLUSION}

I have not been arguing that the legalisation of PAS is more disrespectful to disabled persons than the practice of prenatal testing and selective abortion. Rather, I have argued that the objections launched against expressivism at the beginning of life misfire when we apply them to expressivism at the end of life. Nor have I examined any independent objections one might make against the expressivist argument applied to euthanasia, since my goal has been comparative throughout. Some might object that my argument is too limited because it is merely a comparison and doesn't take a direct stand on the expressivist objection at either the beginning or end of life. But there is some benefit in not biting off more than one can chew. My limited and relative thesis invites agreement from both sides of the expressivist debate, which if achieved would be a fruitful outcome with perhaps important implications. Moreover, the expressivist argument when applied to prenatal testing has gained fierce opposition from bioethicists and scientists who worry about the relief of suffering for future people and the hampering of medical progress. It is, in fact, worthwhile to observe, if the thesis of my paper is correct, that this kind of sustained attack on expressivism fares much worse with respect to PAS: some of the most powerful criticisms in one context look very different in another. We cannot assume just because one kind of expressivism fails that the kind of objection is doomed to fail. And even if the reader still finds my conclusion too limiting, there is still much in the paper that I hope might advance the expressivist debate.

Having shown that the expressivist argument is much better suited to answer objections at the end of life than at the beginning, we still might ask about the importance of this argument. After all, doesn't disrespect and other negative attitudes or beliefs amount to only a slight moral wrong? Don't we express negative beliefs that disvalue others all the time? The reader might be

\footnotetext{
${ }^{\mathrm{xx}}$ Writing about the expressivist objection at the beginning of life, Jonathan Glover argues that in order to avoid expressivist worries we must be committed to fighting all disadvantages, including poverty for example, but should not offer selective abortion for poverty-stricken families because 'there are better ways of dealing with [this] problem' (Glover, p36). ${ }^{37} \mathrm{He}$ does not say why there are not better ways than selective abortion of dealing with disability.
} 
expressing some of these even now about the author-is that any reason to insist that people should be prevented from engaging in these negative beliefs and attitudes?

As a number of defenders of the expressivist argument at the beginning of life have pointed out and as I mention briefly above, there seems to be something more pernicious about having an important social practice express negative beliefs than when private, individual choices do so. Laws, in particular, can express collective moral norms. A law against speeding expresses a norm that one ought not to speed. The decriminalisation of drug use expresses a norm that there is nothing wrong with drug use. And the decriminalisation of assisted suicide laws for persons who experience significant loss of capabilities express that there is nothing wrong with disabled persons taking their own lives. When a negative attitude is embedded in the law, its ability to harm is significantly enhanced. The law's ability to promote a norm that a disabled life is not worth living takes place against a society (and a medical profession) that already underestimates the expected quality of a disabled life. ${ }^{14}$ The decriminalisation or legalisation of assisted suicide or euthanasia might therefore entrench or exacerbate an already-existing negative belief about the disabled.

Moreover, disvaluing the disabled matters because it has the ability to affect another disability rights argument against assisted suicide. As I mentioned in section 1, the most common disability rights case against PAS has not been the expressivist argument. Instead, the concern has been more about the choice to die being coerced and subtly influenced by social pressures. Disability rights advocates object to PAS in order to protect disabled individuals from making a non-autonomous choice to die. ${ }^{324}$ How realistic this objection is depends on how deep the prejudices and social pressures are in society. It is not unreasonable to imagine that the expressivist concern about PAS and euthanasia has a trickle-down effect on any given disabled person's choice to end his life. In other words, the expressivist argument against PAS, if successful, makes the other argument against PAS more serious: if negative attitudes about disabled lives are entrenched or exacerbated, this could make the choice of a disabled person to die even less autonomous than it would otherwise be. Notice, however, that this worry does not apply in the beginning of life context: it is not the case that negative attitudes about disability expressed by prenatal testing will trickle down to embryos or fetuses and cause them to think of themselves as inferior or less valuable. ${ }^{\mathrm{xxi}}$ In this way, the expressivist argument at the end of life is, once again, of more significant concern.

Acknowledgements I presented an earlier version of this paper at a workshop for the Romanell Center for Clinical Ethics and the Philosophy of Medicine at the University of Buffalo in May 2019. I'm grateful to the audience, especially David Hershenov, Peter Koch, and Steve Kershnar, for helpful feedback. I also thank an anonymous referee from Hastings Center Report and an anonymous referee from this journal for instructive comments on a previous version of this paper.

Contributors PR is the sole and exclusive author of this paper.

Funding The authors have not declared a specific grant for this research from any funding agency in the public, commercial or not-for-profit sectors.

Competing interests None declared.

Patient consent for publication Not required.

Provenance and peer review Not commissioned; externally peer reviewed.

Data availability statement There are no data in this work.

\footnotetext{
${ }^{x x i}$ Of course, negative societal attitudes might influence parental choices to undergo prenatal testing and selective abortion, but we might worry far less about those choices being genuinely autonomous ones.
}

\section{REFERENCES}

1 Parens $E$, Asch A. The disability rights critique of prenatal genetic testing. reflections and recommendations. Hastings Cent Rep 1999;29(5):S1-22.

2 Asch A. Why I still haven't changed my mind about prenatal diagnosis: reflections and refinements. In: Asch A, Parens E, eds. Prenatal testing and disability rights. Washington, DC: Georgetown University Press, 2000: 234-58.

3 Coleman D. Not dead yet. In: Foley K, Hendin H, eds. The case against assisted suicide: for the right to end-of-life care. Baltimore, MD: The Johns Hopkins University Press, 2002: 213-37.

4 Ackerman F. Assisted suicide, terminal illness, severe disability, and the double standard. In: Battin MP, Rhodes R, Silvers A, eds. Physician assisted suicide: expanding the debate. New York, NY: Routledge, 1998: 149-61.

5 Keown J, Jackson E. Debating euthanasia. Portland, OR: Hart, 2012.

6 Dees M, Vernooij-Dassen M, Dekkers W, et al. Unbearable suffering of patients with a Request for euthanasia or physician-assisted suicide: an integrative review. Psychooncology 2010;19(4):339-52.

7 Monforte-Royo C, Villavicencio-Chávez C, Tomás-Sábado J, et al. What lies behind the wish to hasten death? A systematic review and meta-ethnography from the perspective of patients. PLoS One 2012;7(5):e37117-16.

8 Emanuel E. Euthanasia and physician-assisted suicide: focus on the data. Med J Aust 2017;206(8):339-40.

9 Oregon Health Authority. Oregon death with dignity act 2017 data summary, 2018

10 National Council on Disability. The danger of assisted suicide laws. Washington, DC, 2019.

11 Buchanan A. Choosing who will be disabled: genetic intervention and the morality of inclusion. Soc Philos Policy 1996;13(2):18-46.

12 Nelson JL. The meaning of the act: reflections on the expressive force of reproductive decision making and policies. Kennedy Inst Ethics $J$ 1998:8(2):165-82.

13 Edwards SD. Disability, identity and the "expressivist objection". J Med Ethics 2004;30(4):418-20.

14 Gill CJ. Health professionals, disability, and assisted suicide: an examination of relevant empirical evidence and reply to Batavia. Psychol Public Policy Law 2000;6(2):526-45.

15 Sade RM, Marshall MF. Legistrothanatry: a new specialty for assisting in death. Perspect Biol Med 1996;39(4):547-9

16 Elliott C. Philosopher assisted suicide and euthanasia. BMJ 1996;313(7064):1088-9.

17 Shakespeare T. Disability rights and wrongs. New York, NY: Routledge, 2006.

18 Malek J. Deciding against disability: does the use of reproductive genetic technologies express disvalue for people with disabilities? I Med Ethics 2010;36(4):217-21.

19 Harris J. Enhancing evolution: the ethical case for making better people. Princeton University Press, 2007.

20 Steinbock B. Disability, prenatal testing, and selective abortion. In: Parens E, Asch A, eds. Prenatal testing and disability rights. Washington, DC: Georgetown University Press, 2000: 108-23.

21 Hofmann B. 'You are inferior!' revisiting the expressivist argument. Bioethics 2017;31(7):505-14.

22 Akhtar S. Respecting embedded disability. J App/ Philos 2016:33(4):363-78.

23 Brock DW. Preventing genetically transmitted disabilities while respecting persons with disabilities. In: Wasserman D, Bickenbach J, Wachbroit R, eds. Quality of life and human difference: genetic testing, health care, and disability. New York, NY: Cambridge University Press, 2005: 67-100.

24 Bickenbach JE. Disability and Life-Ending Decisions. In: Battin MP, Rhodes R, Silvers A, et al, eds. Physician assisted suicide: expanding the debate. New York: Routledge, 1998: 123-32.

25 Parens E, Asch A, eds. Prenatal Testing and Disability Rights. Washington, DC: Georgetown University Press, 2000.

26 Yuill K. Assisted suicide: the liberal, humanist case against legalization. New York, NY: Palgrave Macmillan, 2015.

27 Davis A. A disabled person's perspective on euthanasia. Disabil Stud Q 2004;24(3).

28 Gill CJ. Suicide intervention for people with disabilities: a lesson in inequality. Issues Law Med 1992:8(1):37-53.

29 Scoccia D. The disability case against assisted dying. In: Wasserman DT, Cureton A, eds. The Oxford Handbook of philosophy and disability. New York, NY: Oxford University Press, forthcoming, 2018

30 Wendell S. The rejected body. New York, NY: Routledge, 1996.

31 Murphy TF. When choosing the traits of children is hurtful to others. J Med Ethics 2011;37(2):105-8.

32 Kittay EF, Kittay L. On the expressivity and ethics of selective abortion for disability: conversations with my son. In: Parens E, Asch A, eds. Prenatal testing and disability rights. Washington, DC: Georgetown University Press, 2000: 165-95.

33 Gyngell C, Douglas T. Selecting against disability: the liberal eugenic challenge and the argument from cognitive diversity. J App/ Philos 2018;35(2):319-40.

34 Hurst SA, Mauron A. Assisted suicide and euthanasia in Switzerland: allowing a role for non-physicians. BMJ 2003;326(7383):271-3.

35 Barnes E. The minority body: a theory of disability. New York, NY: Oxford University Press, 2016.

36 Kahane G, Savulescu J. Disability and mere difference. Ethics 2016;126(3):774-88.

37 Glover J. Choosing children: genes, disability, and design. New York, NY: Oxford University Press, 2006. 